\title{
Nonlinear Analysis for Steel Lined Reinforced Concrete Penstock of Manwan Hydropower Station
}

\author{
Ji Dongyu \\ Hunan Urban Construction College \\ Xiangtan, China \\ hnjdy@126.com
}

\author{
Yang Hao \\ North China University of Water Resources and \\ Electric Power \\ Zhengzhou, China \\ 1359396457@qq.com
}

\begin{abstract}
The steel lined reinforced concrete pressure penstock is a new kind of structure design form. Lots of structural model test results and prototype observation data indicate that under initial water pressure stress, the steel lining and outer wrapped concrete shell can work with the good joint, joint bearing. The paper uses general finite element calculation software to do the nonlinear analysis for steel lined reinforced concrete penstock of manwan hydropower station and study three kinds principles: the change principle of the stress of steel lining arising along with the increasing of internal pressure, the elastic-plastic distribution principle of outer wrapped concrete and the crack development principle of concrete. The analysis results indicate that the design project of the steel lined reinforced concrete pressure penstock of manwan hydropower station is reasonable. The structure meets the requirements of strength, which pressure penstock structure will not crack, under the design load. Pressure penstocks meet the requirements of stiffness, that the transformation is small. The structure design is economic and reasonable, safe and reliable.
\end{abstract}

Keywords-Manwan hydropower station; Steel lined reinforced concrete; Penstock; Elastic-plastic analysis; Stress distribution.

\section{OVERVIEW}

The pressure penstocks of manwan hydropower station trace water by single machine and single pipe and have 5 traced water pipes. [1] The power per unit is 250MW. The normal pool level of hydropower station is $994 \mathrm{~m}$. The check flood level is $999.4 \mathrm{~m}$. The level of dead water is $982 \mathrm{~m}$. The manwan hydropower station adopts design of the dam-embedded penstock, whose inner diameter is $7.5 \mathrm{~mm}$ and whose wall thickness is between $16 \mathrm{~mm}$ and $28 \mathrm{~mm}$ and whose wall thickness of calculation section is $24 \mathrm{~mm}[2]$. The elasticity modulus of ASTM662C steel plate produced in Brazil used by the station is $200 \mathrm{Gpa}$ and the yield strength is $330 \mathrm{MPa}$ and the strength of extension is $520 \mathrm{MPa}[3]$. The strength grade of concrete used by dam body is $\mathrm{C} 25$. The strength classes of steel bar is II, whose tangent modulus of elasticity is $200 \mathrm{Gpa}$ and whose Poisson ratio is 0.25 and whose yield strength is $310 \mathrm{MPa}$ and whose secant Young's modulus is $20 \mathrm{Gpa}[4]$.

\section{Calculation Model}

A. Object of Study.

The percentage of steel volume tatio in the engineering calculation project is about $3.8 \%$. Based on the related practical engineering data and stipulate, the initial crack between steel pipe and outer wrapped concrete is set as $1.87 \mathrm{~mm}$ to simulate the effects of construction, temperature variation and creep of concrete[5].

\section{B. Element of Model.}

When the outer wrapped concrete does the nonlinear analysis, the element uses SOLID65, which is specially developed for the inhomogeneous material that its antipressure ability is far bigger than its ability of resistance to tension, like concrete, rock and so on[6]. This element can also be used to other aspects, such as the reinforced composite materials (such as fiberglass) and geological materials (such as rock). The element has 8 nodes, which has 3 degrees of freedom. Steel lining is simulated by shell element, which has 4 nodes that has 6 degrees of freedom[7]. The cracks between steel lining and wrapped concrete are connected by spring elements.

\section{Element of Rebar.}

The paper adopts distributed rebar model, which assumes that rebar in a certain angle distribute in the total element and the coherence between concrete and rebar is fine[8]. Under this assumption, the element is made by homogeneous and continuous materials and the element stiffness matrix contributed by concrete and rebar can be worked out by virtual work equation. The distributed rebar model usually is used to the structures such as shear wall and deep beam, which uses the assumption of biaxial stress. The paper through defines the rebar volume ratio to represent the effects of rebar. This model is easy to adopt and satisfy the precision requirement of engineering.

\section{The Finite Element Model.}

When the finite element analysis method is used to do finite element analysis of pressure pipe, the first job is to establish a finite element method of pressure pipe[9]. The division of finite element of pressure pipe and the simulation scope are shown in Fig.1 and Fig.2. 


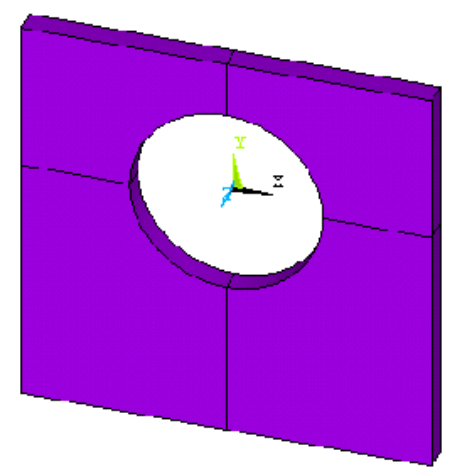

Figure 1. Finite element distribution of the penstock

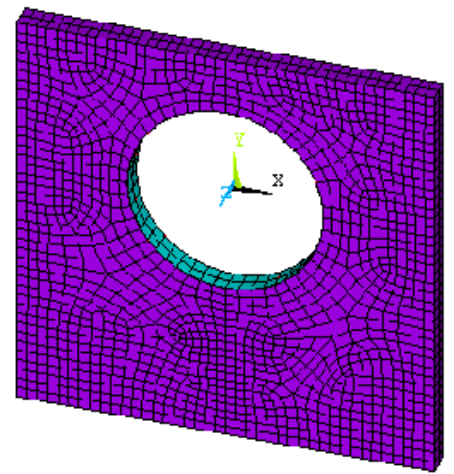

Figure 2. Simulation scope of the penstock model

\section{Structure Analysis OF Penstock}

\section{A Working Condition.}

For studying the force conditions of steel lined reinforced concrete pressure penstock of manwan hydropower station, the simulation calculation mainly considers 4 kinds working conditions[10]: case 1: the value of internal water pressure is $0.56 \mathrm{MPa}$; case 2 : the value of internal water pressure is $0.80 \mathrm{MPa}$; case 3 : the value of internal water pressure is $0.90 \mathrm{MPa}$; case 4 : the value of internal water pressure is $1.00 \mathrm{MPa}$.

\section{B Stress Analysis.}

Through the nonlinear finite element analysis of steel lined reinforced concrete pressure penstock of manwan hydropower station, the paper gets the hoop stress figure of outer wrapped concrete pipe and steel pipe in each working condition, as being shown in the Fig.3 to Fig.9.

NODAL SOLUTION

STEP $=1$

SUB $=1$

TIME $=1$

SY

RSYS $=11$

$\mathrm{DNX}=.004513$

SMN $=.869 \mathrm{E}+08$

$\mathrm{SMX}=.869 \mathrm{E}+08$

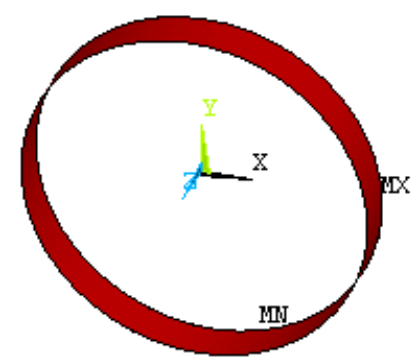

$.869 \mathrm{E}+08$

Figure 3. Circumferential stress cloud map of concrete under case $1(\mathrm{~Pa})$
NODAL SOLUTION

STEP $=1$

SUB $=1$

TIME $=1$

SY

RSYS $=11$

$\mathrm{DNX}=.233 \mathrm{E}-03$

SMN $=-171028$

SIX $=946598$

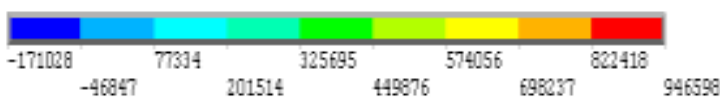

Figure 4. Circumferential stress cloud map of concrete under case $2(\mathrm{~Pa})$

NODAL SOLUTION

STEP $=1$

SUB $=1$

TIME $=1$

SY

RSYS $=11$

$\mathrm{DMX}=1546$

SMN $=-.249 \mathrm{E}+08$

$\operatorname{SMX}=.210 \mathrm{E}+09$

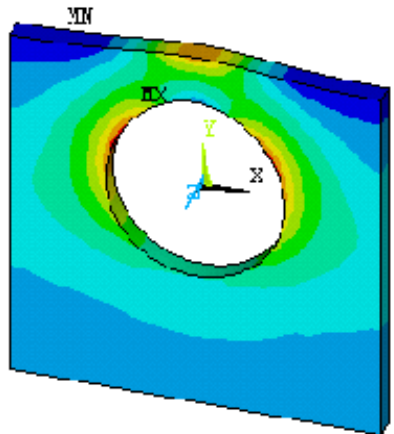

(AVG)
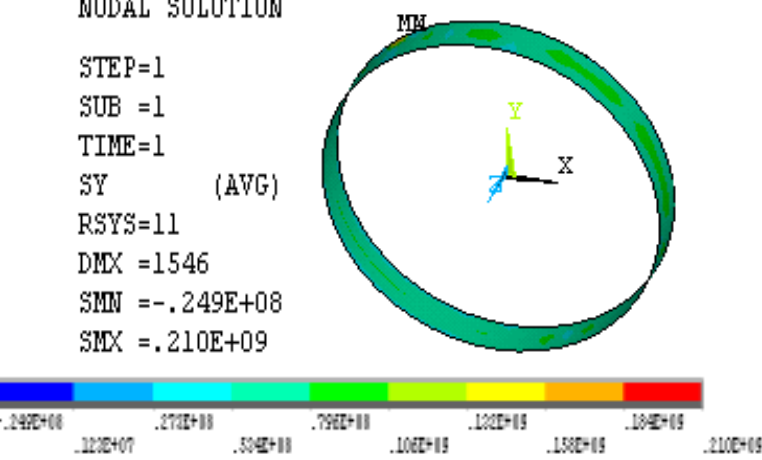

Figure 5. Circumferential stress cloud map of steel pipe under case $2(\mathrm{~Pa})$
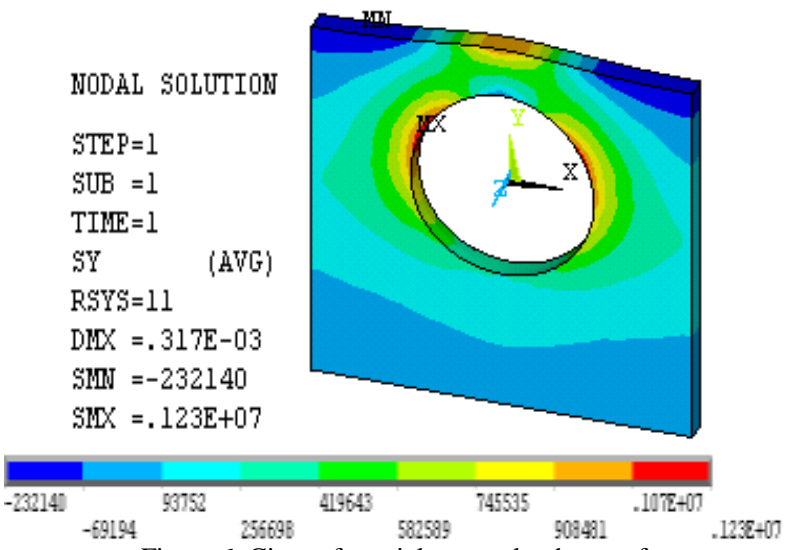

Figure 6. Circumferential stress cloud map of concrete under case $3(\mathrm{~Pa})$

NODAL SOLUTION

STE $P=1$

SUB $=1$

$T I M E=1$

SY

RSYS $=11$

DNX $=14981$

SMN $=-.895 \mathrm{E}+08$

$\operatorname{SIXX}=.228 \mathrm{E}+09$
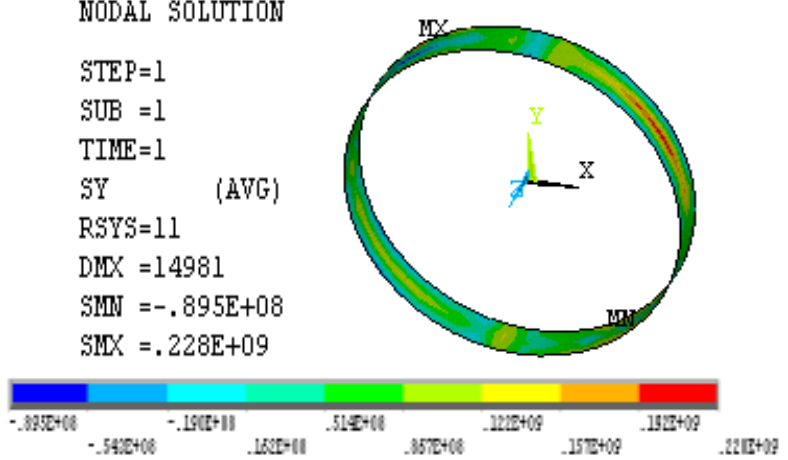

Figure 7. Circumferential stress cloud map of steel pipe under case $3(\mathrm{~Pa})$ 


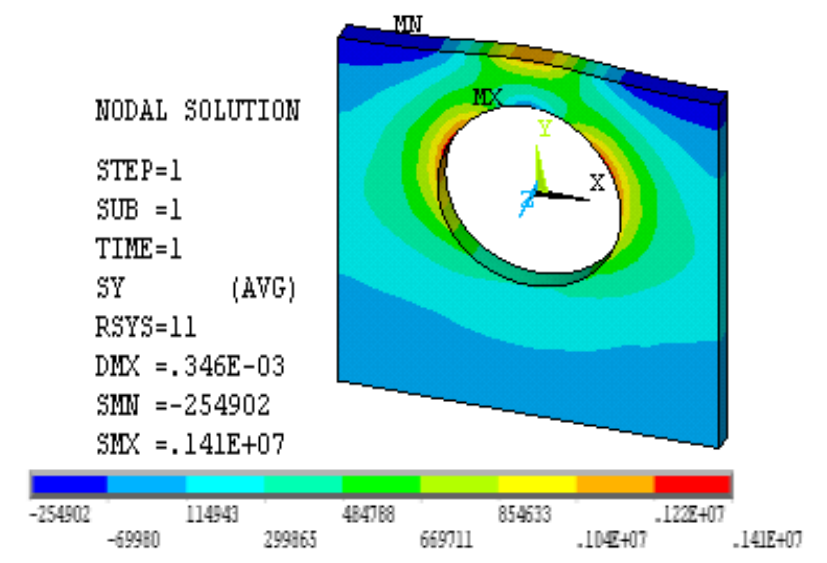

Figure 8. Circumferential stress cloud map of concrete under case $4(\mathrm{~Pa})$

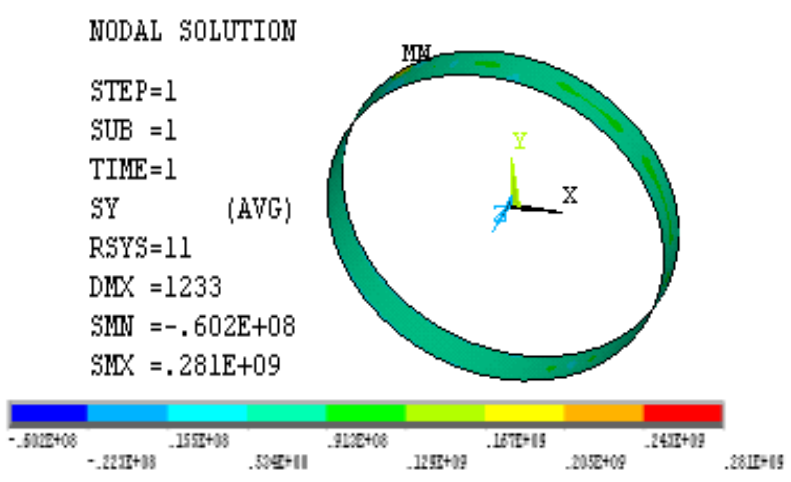

Figure 9. Circumferential stress cloud map of steel pipe under case $4(\mathrm{~Pa})$

It can be seen from Fig.3 to Fig.9, along with the increasing of internal water pressure, the value of hoop stress of steel lining gradually arises and the maximum stress of outer wrapped concrete extends from internal surface to outside, whose reason is that along with the crack of concrete, the internal hoop stress gradually releases.

\section{Deformation Analysis.}

The redial displacement of steel lined reinforced concrete pressure penstock of manwan hydropower station under each working condition is shown in the Fig.10 to Fig.16.

\section{NODAL SOLUTION}

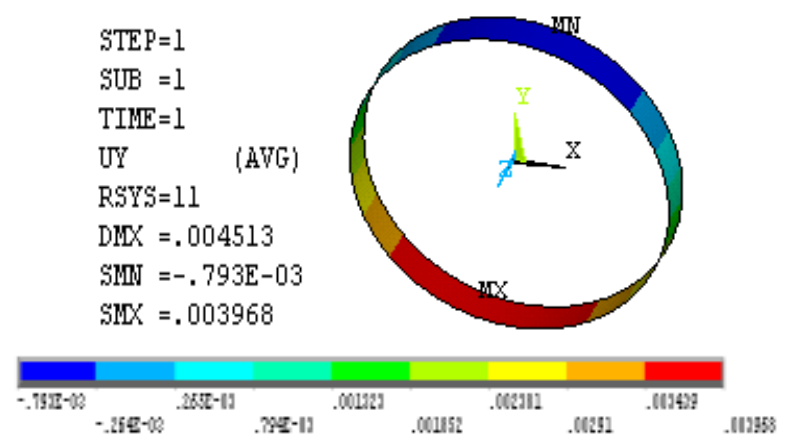

Figure 10. Radial displacement cloud map of steel pipe under case $1(\mathrm{~m})$
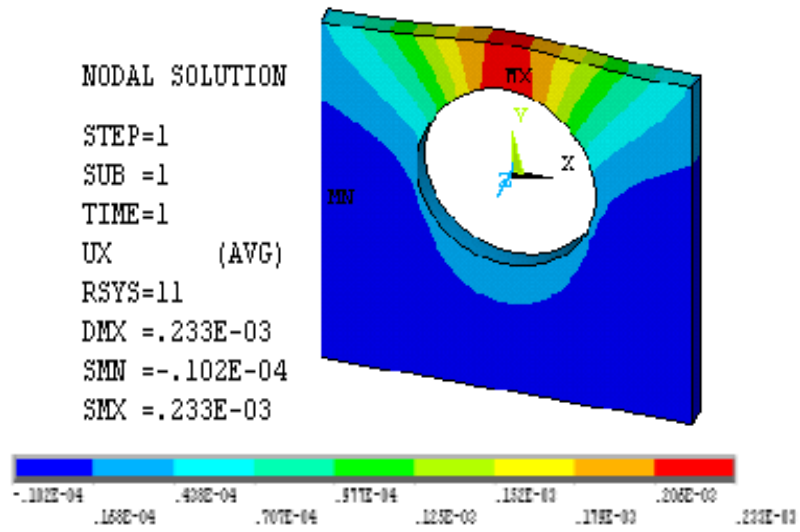

Figure 11. Radial displacement cloud map of concrete under case $2(\mathrm{~m})$

NODAL SOLUTION

$$
\begin{aligned}
& \text { STEP }=1 \\
& \text { SUB }=1 \\
& \text { TIME }=1 \\
& \text { UX (AVG) } \\
& \text { RSYS }=11 \quad \\
& \text { DNX }=1546 \\
& \text { SNN }=.233 E-03 \\
& \text { SNX }=.003093
\end{aligned}
$$

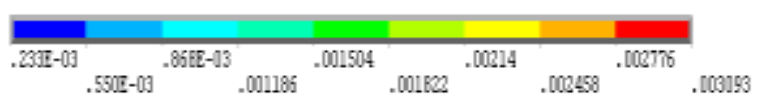

Figure 12. Radial displacement cloud map of steel pipe under case $2(\mathrm{~m})$

NODAL SOLUTION

\section{STEP $=1$}

SUB $=1$

TIME $=1$

UX

(AVG)

RSYS $=11$

DNX $=.317 \mathrm{E}-03$

SMIN $=-.138 \mathrm{E}-04$

SNX $=.317 \mathrm{E}-03$
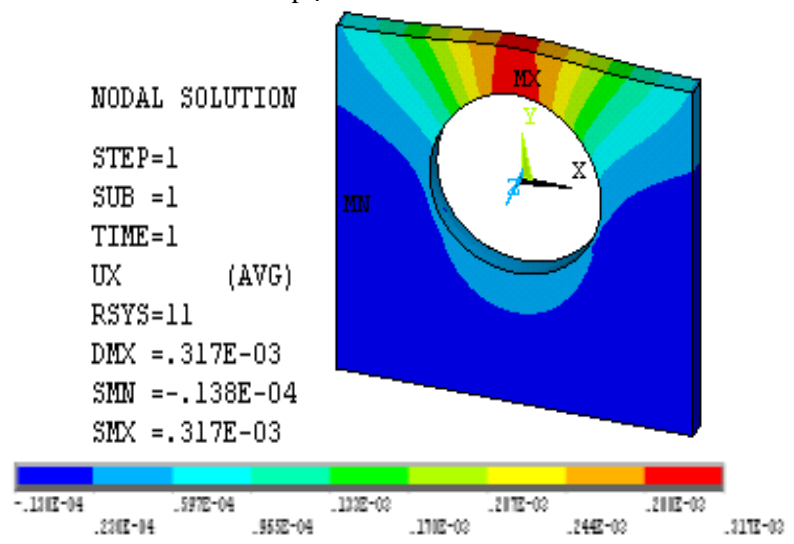

Figure 13. Radial displacement cloud map of concrete under case $3(\mathrm{~m})$

NODAL SOLUTION

STEP $=1$

SUB $=1$

TIME $=1$

$\mathrm{UX}$

RSYS $=11$

DNX $=14981$

SMN $=-.004969$

$\operatorname{SIX}=.00651$

(AVG)
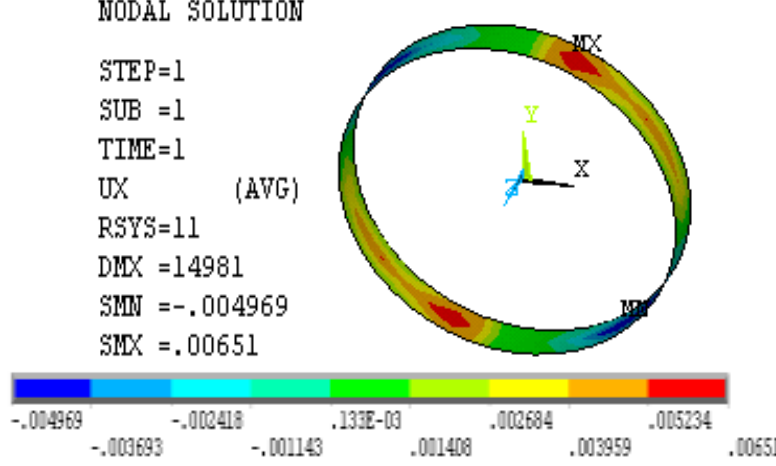

Figure 14. Radial displacement cloud map of steel pipe under case $3(\mathrm{~m})$ 


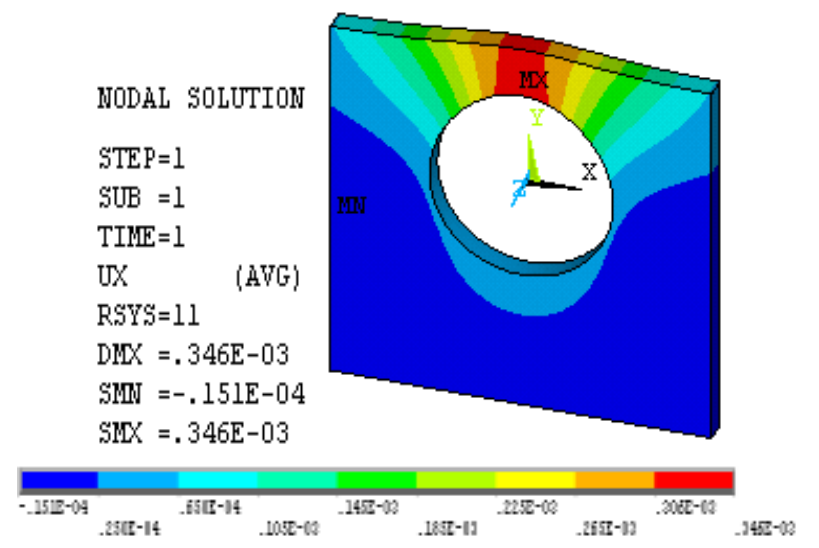

Figure 15. Radial displacement cloud map of concrete under case $4(\mathrm{~m})$

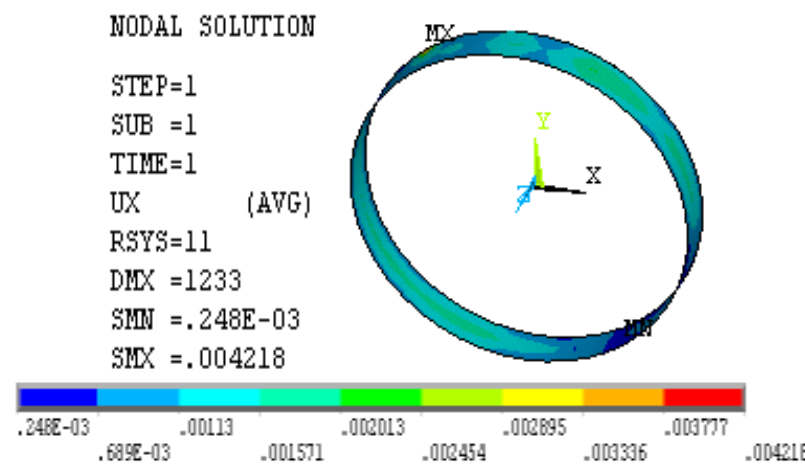

Figure 16. Radial displacement cloud map of steel pipe under case $4(\mathrm{~m})$

It can be seen in the Fig.10 to Fig.16 that redial displacements of steel pipe under each working condition are similar. Under case 1, steel pipe and concrete just now contact, without load delivery, and the concrete does not work. Under case 2 or case 3, concrete and steel pipe bear together, which concrete bears parts of pressure to relieve the pressure of steel lining. Under case 4, the force of concrete exceeds the ultimate tensile strength and load mainly be born by steel lining. It can be got from the process of studying the bear ratio of steel and concrete that the bear ratio of concrete gradually increases before cracking and the bear ratio of concrete decline sharply after cracking.

\section{CONCLUSION}

In conclusion, the design project of steel lined reinforced concrete pressure penstock of manwan hydropower station is reasonable. Under the design load, the pressure pipes do not crack and the structure meets the requirements of strength. The transformation of pressure pipe is small and meet the requirements of stiffness. The structure design project is economic and reasonable, safe and reliable.

\section{REFERENCE}

[1] Hegao Wu, Wei Zhang. Study on wall thickness of steel lined reinforced concrete penstock laid on downstream surface of dam $[\mathrm{J}]$ Journal of hydraulic engineering, 2006, 37(9):1085-1091.

[2] Wei Zhang, Hegao Wu. Safety evaluation of the joint between steel lined reinforced concrete penstock laid on downstream face of dam [J]. Rock and soil mechanics, 2010,31(3):799-804.

[3] Congbao Wang, Hegao Wu. Comparison Analysis of Elasticity Center Method and Finite Element Method for Penstock Laid on Downstream Surface of Dam [J]. Water resources and power, 2005,23(4):8-11.

[4] SL191-2008. Design Code for Hydraulic Concrete Structure[S] China Water Conservancy and Hydropower Press, 2008.

[5] Suohong Jiang. Application of the elasticity center method of structure mechanics for penstock laid on the downstream face of dam [J]. Water power, 2003,29(9):31-34.

[6] Bofang Zhu. Finite Element Method Principle and Application [M] China Water Conservancy and Hydropower Press, 1998.

[7] Xucheng Wang. Finite Element Method [M]. Tsinghua University Press, 2003.

[8] Jianjing Jiang, Xinzheng Lu, Lieping Ye. Finite Element Analysis of Concrete Structures [M]. Tsinghua University Press, 2004.

[9] Min Xia. Research on the crack width formula of steel lined reinforced concrete penstock laid on downstream surface of dam [J]. Concrete, 2011,(9):36-39,43.

[10] Shanding Ma, Ruze Wang. Hydropower Station Structures (The Second Edition) [M]. China Water Conservancy and Hydropower Press, 1996. 